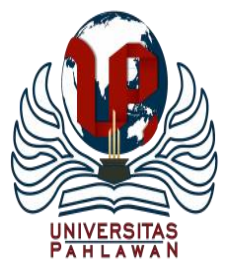

Edukatif : Jurnal Ilmu Pendidikan Volume 3 Nomor 1 Tahun 2021 Halm 20 - 26 EDUKATIF: JURNAL ILMU PENDIDIKAN

Research \& Learning in Education

https://edukatif.org/index.php/edukatif/index

\title{
Analisis Peran Supervisi Akademik Kepala Sekolah kepada Guru IPA di SMP Negeri 20 Kupang
}

\author{
Saldi Salmun Ballu ${ }^{1 凶}$, Lukas Manu², Agus Maramba Meha ${ }^{3}$ \\ Program Studi Pendidikan Biologi, FKIP, Universitas Kristen Artha Wacana Kupang, Indonesia ${ }^{1,2,3}$ \\ E-mail : saldyballu@gmail.com ${ }^{1}$ lukasmanuukaw@gmail.com ${ }^{2}$ us.meha17@gmail.com ${ }^{3}$
}

\begin{abstract}
Abstrak
Salah satu unsur penting dalam pelaksanaan pendidikan adalah kepala sekolah, dimana memiliki tugas dalam mengawasi dan membina pola kegiatan pengajaran yang berlangsung misalnya melakukan supervisi kepada semua guru di sekolah dengan tujuan membantu meningkatkan kualitas pembelajaran dan kinerja dari seorang guru. Seringkali guru mengalami kendala yang beragam yakni bisa timbul dari berbagai faktor sehingga dalam proses pembelajaran kurang optimal. Oleh karena itu, kepala sekolah perlu mengadakan supervisi akademik dalam rangka membantu mengembangkan kompetensi dan profesionalisme guru. Tujuan penelitian ini untuk mengetahui bagaimana supervisi akademik kepala sekolah kepada guru IPA di SMP Negeri 20 Kupang dan kendala pelaksanaan supervisi akademik. Pendekatan yang digunakan adalah pendekatan kualitatif. Teknik pengumpulan data yaitu observasi, wawancara, dokumentasi dan angket. Data dianalisis dengan tahapan reduksi data, penyajian data dan penarikan kesimpulan. Hasil penelitian menunjukkan pelaksanaan supervisi akademik kepala sekolah kepada guru sudah dilakukan dengan baik, kepala sekolah sudah melakukan perencanaan dengan mempersiapkan instrumen supervisi dan menginformasikan jadwal supervisi, pelaksanaan supervisi dengan menggunakan teknik dan prinsip yang beragam. Evaluasi dan tindak lanjut supervisi akademik dilakukan dengan cara hasil supervise didiskusikan dengan guru, sekolah juga mengadakan workshop/pelatihan dengan tujuan adanya perbaikan dan peningkatan kualitas guru dalam menjalankan tugasnya di sekolah. Pelaksanaan supervisi akademik mengalami kendala yang muncul dari guru yaitu kurangnya persiapan perangkat pembelajaran, guru kurang menguasai materi pada saat proses pembelajaran berlangsung dan guru kurang menguasai kelas, dimana terlihat siswa sulit dikendalikan dalam pembelajaran berlangsung.
\end{abstract}

Kata kunci: kepala sekolah, supervisi akademik, guru IPA

\section{Abstract}

One important element in the implementation of education is the principal, who has the task of supervising and fostering the pattern of ongoing teaching activities, for example supervising all teachers in schools with the aim of helping improve the quality of learning and the performance of a teacher. Often teachers experience various obstacles, which can arise from various factors so that the learning process is less than optimal. Therefore, the principal needs to provide academic supervision in order to help develop teacher competence and professionalism. The purpose of this study was to determine how the principal's academic supervision of science teachers at SMP Negeri 20 Kupang and the constraints in implementing academic supervision. The approach used is a qualitative approach. Data collection techniques are observation, interviews, documentation, and questionnaires. The data were analyzed using the stages of data reduction, data presentation, and conclusion drawing. The results showed that the implementation of the principal's academic supervision of the teacher had been carried out well, the principal had planned by preparing the supervision instrument and informing the schedule of supervision, the implementation of supervision using various techniques and principles. Evaluation and follow-up of academic supervision is carried out by discussing the results of supervision with the teacher, the school also holding workshops / training with the aim of improving and improving the quality of teachers in carrying out their duties at school. the implementation of academic supervision experiences obstacles that arise from the teacher, namely the lack of preparation of learning devices, the teacher does not master the material during the learning process and the teacher does not master the class, where it seems that students are difficult to control in the learning process.

Keywords: principal, academic supervision, science teacher

Copyright (c) 2021 Saldi Salmun Ballu, Lukas Manu, Agus Maramba Meha

$\triangle$ Corresponding author

Email : : saldyballu@gmail.com

DOI: https://doi.org/10.31004/edukatif.v3i1.161

ISSN 2656-8063 (Media Cetak) ISSN 2656-8071 (Media Online) 


\section{PENDAHULUAN}

Berdasarkan hasil observasi dan wawancara di SMP Negeri 20 Kupang dengan Kepala Sekolah dan salah seorang guru IPA dikatakan bahwa supervisi dilakukan 3 kali dalam satu tahun ajaran dimana 3 kali supervisi ini dilakukan oleh Dinas setempat dan kepala sekolah. Supervisi yang pertama dilakukan oleh kepala sekolah sendiri sebelum dilakukan oleh dinas bertujuan agar pembenahan-pembenahan dalam sekolah sudah diteliti dengan baik sehingga saat dinas melakukan supervisi sudah diketahui apa saja yang menjadi kendalakendala dalam mencapai tujuan pendidkan di SMP Negeri 20 Kupang sehingga nantinya bisa dibenahi dengan baik. Adapun hal-hal yang akan disupervisi berupa pemeriksaan perangkat pengajaran seperti rencana pelaksanaan pembelajaran, program tahunan, program semester dan silabus, yang kedua teknik pengajaran yang dilakukan guru dalam kelas, dan yang ketiga model pembelajaran, metode pembelajaran dan tata cara mengajar yang di lakukan dalam kelas.

Dalam pemeriksaan perangkat pengajaran yang dinilai dalam RPP adalah tujuan pembelajaran, materi ajar, metode pembelajaran, media pembelajaran, penilaian hasil belajar, Sedangakan pada silabus yang dinilai adalah kompetensi dasar, materi ajar, kegiatan pembelajaran, indikator pencapaian kompetensi, penilaian berupa tes, alokasi waktu, sumber belajar dan program semester yang dinilai adalah kompetensi dasar, indikator, materi pokok, alokasi waktu sedangkan pada program tahunan yang dinilai adalah standar kompetensi, kompetensi dasar, materi pokok, alokasi waktu dan keterangan waktu. Adapun kendala-kendala yang dihadapi dalam pelaksanaan supervisi akademik terdapat pada poin yang ketiga yaitu penerapan model pembelajaran, metode pembelajaran dan tata cara mengajar yang di lakukan dalam kelas. Skor yang diperoleh pada poin ketiga dalam 2 kali supervisi yaitu 79 dan 83. Maka perlu dilakukan supervisi akademik yang lebih baik agar kinerja guru IPA mengalami peningkatan dalam melaksanakan tugas dan tanggung jawab sebagai seorang guru.

Suatu proses pembelajaran dikatakan baik apabila guru melaksanakan tugas dan tanggung jawabnya secara optimal yakni dengan memanfaatkan sumber belajar yang ada dan mampu memiliki daya saing yang tinggi. Namun seringkali guru masih mengalami masalah, kendala yang beragam yakni bisa timbul dari berbagai faktor sehingga dalam proses pembelajaran menjadi kurang optimal. Salah satunya yaitu metode pembelajaran yang digunakan minim dengan variasi yang dapat mendorong peserta didiknya belajar lebih bergairah. Permasalahan seperti ini mengakibatkan suasana pembelajaran di kelas menjadi kaku dan membosankan, dan dapat menimbulkan pembelajaran yang tidak bermutu. Dan akan berdampak pada kualitas pendidikan menjadi rendah. Jika tidak disikapi dengan serius maka dalam pembelajaran IPA kurang dirasakan manfaatnya oleh siswa.

Melihat hal tersebut di atas, maka membutuhkan upaya penanggulangannya. Oleh karena itu Kepala Sekolah perlu mengadakan supervisi akademik dalam rangka mencapai tujuan pendidikan. Supervisi akademik bertujuan mengembangkan situasi kegiatan pembelajaran yang lebih baik ditujukan pada pencapaian tujuan pendidikan sekolah, membimbing pengalaman mengajar guru, mengunakan alat pembelajaran yang modern dan membantu guru dalam menilai kemajuan peserta didik.

Kepemimpinan kepala sekolah merupakan kunci keberhasilan suatu lembaga pendidikan. Kepala Sekolah mempunyai fungsi sebagai tenaga funsional yang diberi mandat atau tugas untuk memimpin suatu sekolah dimana terjadi interaksi antara guru yang memberi mata pelajaran dan peserta didik yang menerima pelajaran. Oleh karena itu Kepala Sekolah memiliki tugas dalam mengontrol pola kegiatan pengajaran yang berlansung misalnya melakukan supervisi. Supervisi kepala sekolah ditujukan kepada guru mata pelajaran yakni dengan tujuan meningkatkan kinerja dari seorang guru (Uhar Suharsaputra, 2018). 
Dalam melakukan supervisi akademik ada beberapa tahap standar proses supervisi yaitu yang pertama pemantauan, dilakukan pada proses pembelajaran berlangsung, tahap kedua supervisi, dilakukan pada saat (perencanaan, pelaksanaan, dan penilaian hasil pembelajaran), tahap ketiga pelaporan, disusun dalam bentuk laporan untuk tindak lanjut, dan tahap keempat tindak lanjut, dilakukan dalam bentuk pemberian penguatan dan penghargaan kepada guru yang menunjukan kinerja yang memenuhi standar serta pemberian kesempatan kepada guru untuk mengikuti program pengembangan keprofesional berkelanjutan (Permendikbud Nomor 22 Tahun 2016).

Berdasarkan permasalahan dan latar belakang di atas maka penulis tertarik melakukan penelitian dengan judul Analisis Peran Supervisi Akademik Kepala Sekolah kepada Guru IPA di SMP Negeri 20 Kupang Tahun Ajaran 2019/2020

\section{METODE PENELITIAN}

Penelitian ini dilakukan menggunakan pendekatan kualitatif. Tempat penelitian adalah SMP Negeri 20 Kota Kupang dan dilaksanakan pada bulan Januari 2020. Subyek penelitian adalah Kepala Sekolah dan guru IPA di SMP Negeri 20 Kupang sebanyak 5 orang. Teknik pengumpulan data yang digunakan dalam penelitian ini yaitu :observasi, wawancara, dokumentas, angket terbuka. Teknik analisis data dilakukan dengan cara pertama reduksi data yaitu merangkum, memilih hal-hal yang pokok, memfokuuskan hal-hal yang penting berkaitan dengan pelaksanaan supervises. Kedua menyajikan data dengan cara mengorganisir informasi secara sistematis untuk mempermudah dalam menggabungkan dan merangkai keterikatan antar data dalam menyusun penggambaran proses supervise di sekolah, ketiga penarikan kesimpulan.

\section{HASIL DAN PEMBAHASAN PENELITIAN}

Dalam pelaksanaan kegiatan supervisi akademik oleh kepala sekolah kepada guru IPA di SMP Negeri 20 Kupang terdapat beberapa langkah seperti pada uraian pendapat berikut. Untuk mencapai tujuan pendidikan peran kepala sekolah sebagai supervisor sangatlah penting karena supervisi akademik adalah suatu kegiatan yang dilakukan kepala sekolah untuk memperbaiki proses pembelajaan agar mencapai standar yg ditentukan dan mencapai proses pembelajaran yang lebih baik. Menurut (Dwikurnaningsih, 2018) langkahlangkah dalam melaksanakan supervisi akademik sebagai berikut:

\section{Perencanaan Supervisi Akademik}

Dalam melakukan supervisi akademik kepala sekolah perlu merencanakan kegiatan supervisi yang akan dilakukan. Menurut (Asf Jasmani dan Zaiful Mustofa, 2013). Langkah pertama adalah perencanaan supervisi akademik yang terbagi atas beberapa tahap yaitu tahap Informasi waktu sebelum supevisi, Tahap perencanaan supervisi akademik berikutnya adalah persiapan atau perencanaan merupakan tahap dimana kepala sekolah merencanakan waktu pelaksanaan supervisi, guru yang menjadi sasaran dan teknik yang akan diterapkan selama supervisi dilakukan. Setelah merencanakan waktu supervisi kepala sekolah menginformasikan waktu kepada guru dimana informasi waktu adalah suatu informasi kepada guru yang bersangkutan agar dapat menyesuaikan dan mengetahui waktu supervisi sehingga guru dapat mempersiapkan diri untuk disupervisi.

Informasi waktu sebelum pelaksanaan supervisi akademik yang ada di SMP Negeri 20 Kupang sudah dilaksanakan dengan baik sesuai dengan hasil wawancara peneliti dengan informan yakni kepala sekolah dan guru IPA. Dimana informasi waktu dari jauh hari dan sesuai jadwal supervisi yang sudah ditentukan dari Kepala Sekolah kepada guru IPA dengan tujuan agar guru dapat menyiapkan segala 
sesuatu yang berkaitan dengan supervisi akademik misalnya materi, perangkat pembelajaran, media, metode, bahan ajar, dan hal-hal lain yang berkaitan dengan supervisi akademik yang akan dilakukan.

Tahap perencanaan supervisi akademik selanjutnya yaitu persiapan sebelum pelaksanaan supervisi. persiapan dalam pelaksanaan supervisi akademik memerlukan adanya persiapan dari Kepala Sekolah maupun guru dimana kepala sekolah sebagai supervisor menyiapkan perangkat yang berkaitan dengan supervisi akademik sedangkan guru yang disupervisi menyiapkan perangkat yang akan dinilai sehingga pelaksanaannya dapat dilaksanakan dengan baik atau sesuai dengan ketentuan-ketentuan yang ada. Berdasarkan hasil wawancara peneliti dengan informan yakni kepala sekolah dan guru IPA bahwa Instrumen penilaian supervisi merupakan hal yang perlu disiapkan oleh kepala sekolah sebagai supervisor sedangkan guru yang disupervisi harus menyiapkan segala sesuatu yang berkaitan dengan kelengkapan administrasi pembelajaran seperti RPP (Rencana Pelaksanaan Pembelajaran), silabus, metode pembelajaran, alat dan bahan serta penggunaan media pembelajaran yang tepat disesuaikan dengan materi yang akan diajarkan.

\section{Pelaksaan Supervisi Akademik}

Setelah melakukan perencanaan supervisi akademik langka selanjutnya adalah pelaksanaan supervisi. Berdasarkan hasil dari angket yang diberikan kepada kepala sekolah menyatakan pelaksanaan supervisi yang dilakukan di SMP Negeri 20 Kupang adalah dua kali dalam satu semester yaitu pertama supervisi perangkat pembelajaran dan kedua supervisi klinis atau supevisi yang dilakukan pada saat guru melakukan pembelajaran dikelas. Supevisi perangkat pembelajaran adalah supervisi yang dilakukan dengan memeriksa perangakat pembelajaran yang akan dipakai guru dalam pembelajaran dengan tujuan agar hal-hal yang masih kurang mengenai perangkat pembelajaran dapat diperbaiki sedangkan supervisi klinis yaitu supervisi yang dilakukan dengan pengamatan langsung kegiatan belajar mengajar sebenarnya dan melibatkan tatap muka dan interaksi antara supervisor dan guru yang disupervisi serta berusaha mengembangkan langka-langka selanjutnya menuju perbaikan kinerja.

Dalam Pelaksanaan supervisi akademik ada beberapa aspek yang harus dipakai oleh kepala sekolah. Menurut (Sari, A. L., \& Sukoco, 2015) keefektifan supervisi akademik ditinjau dari dimensi pelakasanaan meliputi beberapa aspek yaitu ketetapan dalam penerapan prinsip-prinsip dan teknik dalam melaksanakan supervisi. Aspek yang pertama yaitu prinsip yang digunakan dalam supervisi, dalam melaksanakan supervisi akademik yang dilakukan oleh kepala sekolah atau supervisor harus dengan berdasarkan prinsip-prinsip supervisi akademik yang ada agar pelaksanaannya benar-benar efektif atau sesuai dengan ketentuan-ketentuan supervisi akademik. Prinsip yang dipakai kepala sekolah dalam supervisi di SMP Negeri 20 Kupang sesuai dengan hasil wawancara peneliti dengan informan yakni kepala sekolah dan guru IPA yaitu prinsip objektif artinya memberikan masukan sesuai dengan aspekaspek yang ada pada instrumen dan prinsip humanis artinya mampu menciptakan hubungan kemanusiaan yang harmonis, terbuka, jujur, dan antusias.

Kegiatan supervisi akademik yang dilaksanakan di SMP Negeri 20 Kupang oleh kepala sekolah atau supervisor menggunakan prinsip humanis artinya mampu menciptakan hubungan yang harmonis, terbuka, jujur, antusias dan penuh sabar dan prinsip ojektif yang artinya supervisi dilakukan sesuai aspekaspek instrumen dan harus dilaksanakan atas hubungan profesional antra supervisor dengan guru yang disupervisi, bukan atas dasar hubungan pribadi. 
Selanjutnya aspek yang kedua yaitu teknik-teknik dalam pelaksanaan supervisi akademik, dalam melaksanakan supervisi akademik kepala sekolah sebagai supervisor menggunakan teknik supervisi, oleh karena itu setiap kepala sekolah sebagai supervisor haruslah memiliki ketrampilan dan kemampuan yang memadai dalam menerapkan teknik supervisi yang tepat dalam melaksanakan supervisi akademik didalam kelas. Penggunaan teknik yang dipakai kepala sekolah kepada guru IPA di SMP Negeri 20 Kupang yaitu teknik perseorangan atau teknik individual. Teknik supervisi ini dilakukan oleh kepala sekolah pada saat guru melakukan proses pembelajaran dikelas dengan menggunakan instrumen supervisi.

Menurut (Lie et al., 2013) teknik pelaksanaan supervisi akademik yang dilakukan kepala sekolah sesuai dengan kebuthan guru yang disupervisi, teknik yang sering digunakan adalah teknik individual, baik pertemuan individu, kunjungan kelas ataupun observasi kelas. Teknik supervisi individual dilakukan kepala sekolah untuk mengatasi permasalahan yang dihadapi guru dalam hal memyusun kegiatan belajar mengajr, memilih metode pembelajaran yang tepat dan penggunaan sumber belajar.

\section{Evaluasi Supervisi Akademik}

Setelah melakukan supervisi akademik kepala sekolah terhadap guru maka langkah berikutnya adalah evaluasi. Evaluasi terbagi atas beberapa tahap yaitu yang pertama evaluasi dalam supervisi akademik yang dilakukan oleh kepala sekolah atau supervisor terhadap guru bertujuan untuk memperbaiki segala hal yang kurang dari kinerja guru di kelas baik secara akademis ataupun tingkah laku dan keaktifan. Evaluasi kepala sekolah dapat dilakukan dengan berbagai cara jika evaluasi dilakukan secara bersamaan atau kepada banyak guru, maka evaluasi dilakukan secara kelompok atau diadakan rapat pada akhir bulan atau akhir semester dan evaluasi juga dapat dilakukan secara perseorangan atau individu.

Menurut (Lie et al., 2013) dalam evaluasi sangat penting bagi kepala sekolah untuk mengetahui kemampuan dan kelemahan guru dalam proses pembelajaran, karena sasaran utama supervisi akademik adalah kemampuan guru dalam merencanakan, melaksanakan, kegiatan pembelajaran, dan melakukan penilaian hasil pembelajaran, dan dapat memanfaatkan hasil penilaian untuk meningkatkan proses pembelajaran, serta dapat menciptakan lingkungan belajar yang menyenangkan, dengan cara memanfaatkan sumber belajar yang tersedia dan mengembangkan interaksi pembelajaran (strategi, metode dan teknik) yang tepat.

Evaluasi yang dilakukan di SMP Negeri 20 kupang oleh kepala sekolah terhadap guru IPA adalah evaluasi secara individu atau perseorangan yaitu kepala sekolah memanggil guru IPA dan menyampaikan kelemahan - kelemahan pada kinerja guru yang bersangkutan dan membahas cara memperbaikinya untuk meningkatkan kinerja guru dalam kegiatan pembelajaran kedepannya. Adapun hasil penilaian supervisi kepala sekolah terhadap kinerja guru di SMP Negeri 20 Kupang yaitu kriteria yang didapatkan adalah dua orang guru memiliki kriteria Baik sedangkan satu guru memiliki kriteria Sangat Baik.

Setelah melakukan evaluasi langka selanjutnya kepala sekolah melakukan tindak lanjut supervisi, tindak lanjut supervisi akademik, merupakan akhir dari pelaksanaan kegiatan supervisi. Pelaksanaan supervisi akademik diharapkan adanya tindak lanjut dengan tujuan adanya perubahan yang dialami oleh seorang guru setelah disupervisi oleh kepala sekolah, seperti guru semakin profesional dalam mengajar 
sehingga hasil belajar siswa meningkat. Menurut (Karsiyem \& Wangid, 2015) tindak lanjut supervisi sangat penting baik bagi guru sendiri maupun kepala sekolah. Oleh karena itu, tindak lanjut perlu dilaksanakan. Tindak lanjut merupakan bagian dari siklus pelaksanaan supevisi yang efektif, maka dari itu tindak lanjut ini perlu direncanakan, dilakukan dan dievaluasi oleh kepala sekolah agar supevisi benar-benar dapat memberikan dampak positif bagi guru dalam memperbaiki kinerja.

Tindak lanjut yang dilakukan oleh kepala sekolah di SMP Negei 20 kupang yaitu kepala sekolah memberikan hasil kepada guru yang disupervisi agar dapat memperbaiki kesalahan dan kekurangan yang ada serta memberikan pujian untuk guru yang melaksanakan pembelajaran yang baik. Selain itu tindak lanjut supervisi akademik dilakukan dengan mengadakan workshop yang dilakukan oleh dinas kepada semua guru termasuk guru IPA.

\section{Manfaat Supervisi Akademik}

Setelah melakukan supervisi akademik maka dapat dirasakan manfaatnya baik kepala sekolah maupun guru IPA. Manfaatnya terhadap kinerja guru sangat besar sesuai dengan pengertian supervisi akademik yaitu serangkaian kegiatan untuk membantu guru dalam mengelolah proses pembelajaran dan juga membantu meningkatkan mutu pendidikan, meningkatkan kualitas kinerja atau profesionalisme guru, dan meningkaatkan situasi pembelajaran dalam kelas. Supervisi akademik bermanfaat dalam memberikan pelayanan supervisi pengajaran kepada guru untuk menumbuhkan proses belajar mengajar yang berkualitas baik, menyenangkan, inovatif dan dapat menjaga keseimbangan pelaksanaan tugas saat mengajar (Sagala, 2012). Manfaat supervisi akademik terhadap kinerja guru di SMP Negeri 20 Kupang sangat membantu guru dengan adanya supervisi akademik guru dapat mengetahui kemampuannya dalam mengelolah pembelajaran di kelas, kemampuan menguasai materi dikelas dan sebagai pembelajaran bagi guru untuk meningkatkan kinerjanya.

\section{Kendala-Kendala Dalam Pelaksanaan Supervisi Akademik.}

Pelaksanaan supervisi akademik yang dilakukan oleh kepala sekolah atau supervisor terhadap guru sudah dilakukan dengan baik, Namun pada kenyataannya masih terdapat kendala-kendala yang mempengarui pelaksanaan supervisi akademik, kendala tersebut berasal dari guru itu sendiri dan dukungan dari lokasi atau sekolah. Faktor yang mempengaruhi kinerja seseorang dapat berasal dari individu itu sendiri seperti motivasi, keterampilan dan juga pendidikan, juga faktor dari luar individu, iklim kerja, tingkat gaji, tempat kerja dan lain sebagainya (Asf Jasmani dan Zaiful Mustofa, 2013).

Dalam pelaksanaan supervisi akademik di SMP Negeri 20 Kupang terdapat kendala-kendala yang ditemukan dalam pelaksanaan supervisi akademik terhadap guru yaitu kurangnya persiapan dari guru yang disupervisi, guru kurang menguasai materi, pemanfaatan waktu pembelajaran yang kurang efektif, siswa yang kurang fokus dan susah diatur, guru belum menguasai kelas secara utuh. Kendala lain yaitu kurangnya dukungan dari sekolah berupa media pembelajaran dan alat dan bahan laboratorium sebagai sumber belajar. Dengan demikian pelaksanaan supervisi akademik di SMP Negeri 20 kupang masih memiliki kendala, kendala tersebut muncul dari individu atau guru yang disupervisi terkait kemampuan guru dan dukungan dari sekolah.

\section{KESIMPULAN}

Pelaksanaan supervisi akademik dilakukan dengan baik dimana kepala sekolah sudah melakukan perencanaan dengan mempersiapkan intrumen dan jadwal pelaksanaan supervisi yang dilaksanakan menggunakan teknik dan prinsip yang beragam, dan juga telah dilakukan evaluasi dan tindak lanjut supervisi 
akademik dengan mengadakan diskusi bersama guru dan sekolah juga telah mengadakan workshop dalam rangka meningkat kompetensi guru. Kendala yang ditemukan selama pelaksanaan supervisi yaitu kurangnya persiapan guru dalam mempersiapkan perangkat dan materi pembelajaran, guru juga kurang menguasai materi pada saat proses pembelajaran berlangsung dan guru kurang menguasai kelas.

\section{UCAPAN TERIMA KASIH}

Penulis mengucapkan terima kasih kepada semua pihak yang telah membantu dalam penelitian ini, terlebih khusus untuk kedua pembimbing saya.

\section{DAFTAR PUSTAKA}

Asf Jasmani dan Zaiful Mustofa. (2013). Supervisi Pendidikan. Yogyakarta: Ar-Russ Media.

Dwikurnaningsih. (2018). Dalam meningkatkan Kualitas Pembelajaran di SD Yari Program Studi Magister Manajemen Pendidikan Fakultas Keguruan dan Ilmu Pendidikan Universitas Kristen Satya Wacana NWH Hartana SDN I Prigi Kedungjati. 2, 101-111.

Indonesia, U., Ruswenda, U. U. S., Ilmu, F., Dan, S., Politik, I., Studi, P., Administrasi, I., Administrasi, K., \& Kebijakan, D. A. N. (2011). Berbagai Faktor Dalam Supervisi Akademik Pengawas Sekolah Menengah Kejuruan (Smk) Di Kabupaten Kuningan.

Karsiyem, K., \& Wangid, M. N. (2015). Pelaksanaan Supervisi Akademik Dalam Peningkatan Kinerja Guru Sekolah Dasar Gugus Iii Sentolo Kulon Progo. Jurnal Akuntabilitas Manajemen Pendidikan, 3(2), 201212. https://doi.org/10.21831/amp.v3i2.6337

Lie, K. M., Radiana, U., \& Djudin, H. T. (2013). Pelaksanaan Supervisi Akademik oleh Kepala Sekolah dalam Upaya Pembinaan Profesionalisme Guru di SMA. Jurnal Pendidikan Dan Pembelajaran, 2(3), 117 .

Rosyadi, Y. I. (2015). Jurnal Akuntabilitas Manajemen Pendidikan Tersedia Online : http://journal.uny.ac.id/index.php/jamp. Jurnal Akuntabilitas Manajemen Pendidikan, 3(1), 124-133.

Sagala, S. (2012). Supervisi Pembelajaran dalam Profesi Pendidikan. Bandung: Alfabeta.

Sari, A. L., \& Sukoco, S. (2015). Keefektifan Supervisi Akademik Oleh Kepala Sekolah Dasar Negeri SeKecamatan Talang Empat Bengkulu Tengah. Jurnal Akuntabilitas Manajemen Pendidikan, 3(1), 1-12.

Uhar Suharsaputra. (2018). Supervisi Pendidikan. Bandung: Refika Aditama. 